\title{
Projeto Metrô+Música: intencionalidades, disponibilidades e embates
}

SUBWAY+MUSIC PROJECT: INTENTIONALITIES, AVAILABILITIES AND CLASHES

\section{Júlia Lúcia de Oliveira Albano da Silva}

https://orcid.org/0000-0002-1128-9917

(Universidade de Santo Amaro - UNISA; Centro Universitário - FECAP, Brasil)

\section{Resumo}

Este trabalho aborda o projeto Metrô+Música desenvolvido pelo Metrô de São Paulo entre junho de 2018 e fevereiro de 2019. O objetivo é compreender o que a iniciativa pode nos indicar sobre a relação entre o som e as pessoas que fazem uma megacidade como São Paulo. Para a coleta de dados recorremos às reportagens publicadas em diferentes mídias e às informações do Metrô. A pesquisa bibliográfica é composta por Ferrara para a apreensão da cidade, para a abordagem sobre o som e o ouvir recorremos a Baitello e Menezes.

Palavras-chave: Som. Metrô+Música.Cidade.

\section{Abstract}

This paper addresses the Metro + Music project developed by the São Paulo Metro between June 2018 and February 2019. The objective is to understand what the initiative can tell us about the relationship between sound and people who are doing a megacity like São Paulo. . For data collection we resorted to reports published in different media and information from Metrô. The bibliographical research is composed by Ferrara for the apprehension of the city, for the approach to the sound and the hearing we resorted to Baitello and Menezes.

Keywords: Sound. Subway + Music. City. 


\section{Introdução}

Em nota divulgada no dia 10 de fevereiro de 2019, o Metrô da cidade de São Paulo informou que não manteria a veiculação de músicas dentro dos vagões dos trens e nas estações. Sem mais detalhes, o sistema se limitou a informar que a ação chamada de Metrô+Música era um projeto experimental e seria descontinuado por não ser viável. Assim, como na implementação e durante o período de sete meses em que ficou atuante, o encerramento da iniciativa dividiu a opinião dos usuários. Para os que criticavam a prática, a descontinuidade foi um alívio, enquanto para os apoiadores, era um recurso a menos para lidar com o estresse diário de quem vive na cidade mais populosa do país ${ }^{1}$.

Se há algo que podemos afirmar sobre o impacto promovido pelo Projeto Metrô + Música é que a iniciativa gerou uma intensa repercussão, expressa, sobretudo, por meio das redes sociais digitais nas quais os usuários registravam reações positivas ou negativas a respeito da presença de música durante a viagem nos vagões do Metrô. Mas como nos ensinou John Cage, o ruído também pode ser compreendido como manifestação musical. Portanto, da cacofonia e dos embates de opiniões discordantes de usuários, de diversas mídias eletrônicas e digitais e da Companhia do Metropolitano de São Paulo - Metrô, o que nos parece relevante é que o som esteve (ainda que de forma tímida) na pauta das discussões que envolvem cidade, mobilidade e convivência social.

As singularidades enquanto fenômeno físico, o modo de atuação enquanto estímulo, a potencialidade e funcionalidade do som na interação com os espaços da cidade e os cidadãos, ocupam modesto espaço nas reflexões sobre a cidade. Portanto, como parte de um projeto em desenvolvimento, este artigo tem como objetivo central compreender o que a implantação, o desenvolvimento e a interrupção do projeto Metrô+Música pode nos indicar sobre a relação entre o som e as pessoas que vivenciam e fazem concreta e cotidianamente uma megacidade como São Paulo.

Metodologicamente optamos por uma pesquisa documental, bibliográfica, além de observação em campo. A partir de uma postura etnográfica percorremos as linhas de trens envolvidas pelo Projeto Metrô+Música observando e registrando as reações e relações dos usuários com a música dentro dos vagões. Para a coleta de dados sobre o projeto

\footnotetext{
${ }^{1}$ São Paulo é a cidade mais populosa do Brasil, com 12,2 milhões de habitantes. Os dados são do Instituto Brasileiro de Geografia e Estatística (IBGE). Disponível em: https://cidades.ibge.gov.br/brasil/sp/sao-paulo/panorama. Acesso em 20 Mar 2019.
} 
recorremos às reportagens publicadas em mídias eletrônica e digital e às informações da Companhia do Metropolitano de São Paulo - Metrô, obtidas por meio da Lei de Acesso à Informação. A pesquisa bibliográfica tem como norteador a dinâmica dos fixos e dos fluxos de Lucrécia D'Alessio Ferrara para a apreensão da cidade como um organismo vivo e em constante transformação, para a abordagem sobre as particularidades e características do som, do ouvir e do ambiente comunicacional recorremos aos estudos de Murray Schafer, Norval Baitello Jr. e José Eugenio Menezes.

\section{Metrô de São Paulo: mobilidade sobre trilhos}

A Companhia do Metropolitano de São Paulo - Metrô, inaugurada em abril de 1968, está inserida na matriz de transporte da Região Metropolitana e conta com seis linhas que totalizam 97,1 quilômetros de trilhos e 86 estações $^{2}$. Está sob o controle do Governo do Estado de São Paulo e sob gestão da Secretaria de Estado de Transportes (STM). A Companhia atualmente é responsável pela operação e manutenção das linhas 1Azul, 2- Verde, 3- Vermelha e 15- Prata. A linha 4-Amarela é operada pela concessionária ViaQuatro e as linhas 5- Lilás e 17- Ouro pela ViaMobilidade, ambas atuam no sistema de Parcerias Público-Privadas, ou seja, no âmbito do contrato firmado com o Governo de São Paulo em regime de concessão.

A Companhia é nomeada pelos usuários pelo tipo de transporte que oferece, portanto, é conhecida como "Metrô" e para compreendermos a dimensão do que representa a rede metroviária de São Paulo é importante que conheçamos alguns números. De acordo com o Relatório Integrado de $2018^{3}$, foram transportados por dia útil uma média de 3,7 milhões de pessoas e esse número aumenta em $60 \%$ quando comparado à média dos dias úteis de maio de 2019 que contabilizou 5.978 milhões de usuários. ${ }^{4}$ Atualmente, $57 \%$ dos usuários é composto por mulheres, 58\% por jovens entre 18 e 34 anos e 49\% com instrução de Ensino Médio completo. A grande maioria, ou seja, 89\% são usuários

${ }^{2}$ Enquanto São Paulo é a cidade da América com maior número de habitantes e tem 96 quilômetros de metrô, Cidade do México que é a segunda em número de habitantes tem 202 quilômetros. Nova Iorque que ocupa o quarto lugar tem ${ }^{4} 18$ quilômetros de malha metroviária urbana.

${ }_{3}$ Relatório Integrado 2018. Disponível em: http:/www.metro.sp.gov.br/metro/institucional/pdf/rel-integrado.pdf . Acesso em 17 Jun 2019.

${ }^{4}$ Diretoria de Operações/Coordenadoria de informações Gerenciais e Estudos Estratégicos. Disponível em: https:// transparencia.metrosp.com.br/dataset/demanda/resource/c2f6405f-b487-4bbb-b1d1-2781276d016c.. Acesso em: 12 Jun 2019. 
habituais do Metrô, o que significa que usam três dias ou mais na semana. Outro dado relevante é que $82 \%$ são usuários de outra condução, ou seja, usam o Metrô conjugado com outro modal como ônibus 5 .

A questão relativa à infraestrutura da mobilidade nas grandes cidades brasileiras é reconhecidamente complexa, abrange inúmeros fatores, interesses e tensões, e tem sido presença constante nas promessas de candidatos e nos planos de governos constituídos. Estratégia ou não, é difícil ignorar a questão da mobilidade quando à urbanização, de uma forma global, é tida como "uma das tendências mais transformadoras do século XXI" 6 .

Particularmente sobre o Brasil, o último censo do IBGE de $2010^{7}$ informa que 84,4\% da população vive em áreas urbanas, e a estimativa do Programa das Nações Unidas para Assentamentos Humanos, ONU-Habitat, é que mais de 90\% da população brasileira viverá em cidades até o ano de 2030.

Nesse cenário, a expansão e garantia de acesso à infraestrutura que viabilize o deslocamento seguro, eficiente e de qualidade nas grandes cidades é um desafio concreto e presente dentre as demandas dos gestores públicos e na pauta de entidades envolvidas com a mobilidade sustentável e ativa ${ }^{8}$. Na principal capital do país, mais especificamente no sistema metroviário, além de recorrer ao modelo de Parceria Público-Privada (PPP) e à forma de concessão para ampliar a rede e gerir o transporte sobre trilhos da cidade, em 2018 o governo de São Paulo resolveu apostar na música como estratégia para "diminuir o nível de estresse" dos usuários.

\section{Projeto Metrô+Música: implantação e embates}

No dia 9 de julho de 2018, o Metrô de São Paulo iniciou o projeto Metrô+Música que consistia na veiculação de música em estações e trens das linhas 1-Azul, 2-Verde e 3-Vermelha. A proposta foi implantada de forma progressiva em estações como Sé (Linha

${ }^{5}$ Perfil do Usuário Caracterização Socioeconômica do Usuário e seus hábitos de Viagem 2018. Disponível em: http://www.metro.sp.gov.br/metro/numeros-pesquisa/perfil-usuario.aspx. Acesso em: 17 de jun. 2019.

${ }^{6}$ Nova Agenda Urbana 2016. Disponível em: $<$ http://habitat3.org/wp-content/uploads/NUA-Portuguese-Brazil.pdf?fbclid=IwAR2koIM7MtgBh6i57G4fxWeWpbK52Jr7sXIrGdBbJF81bF2GSzY527FWdAY>. Acesso em: 17 de jun. 2019.

${ }^{7}$ IBGE, Censo 2010. Disponível em: https://censo2010.ibge.gov.br/. Acesso em: Ab. 2019.

${ }^{8}$ Mobilize Brasil é um portal brasileiro de conteúdo exclusivo sobre Mobilidade Urbana Sustentável. Além de disponibilizar conteúdo abrangente e de diversas formas sobre mobilidade urbana sustentável, reúne Campanhas, Projetos, Blogs, Iniciativas e ONGs envolvidos com a questão da mobilidade nas cidades brasileiras. Disponível em: https://www.mobilize.org.br/. Acesso em: 20 Ab. 2019. 
1-Azul e 3-Vermelha), São Bento (linha 1-Azul), Paraíso (linha 1-Azul e 2-Verde), Vila Madalena (2-Verde), Corinthians-Itaquera (linha 3-Vermelha) e em 14 trens que passaram a veicular a playlist com 200 músicas no interior de seus vagões. Durante os setes meses de funcionamento, o projeto alcançou 55 das 86 estações do sistema metroviário e a playlist era composta por canções instrumentais que iam do jazz, passando pela MPB, bossa nova, música erudita e samba.

O governo paulista, responsável pela gestão do Metrô, desembolsou cerca de R\$ 39 mil por mês. O valor era pago à ONG Instituto de Cultura e Cidadania (ICULT), responsável pela manutenção do projeto e pelo recolhimento dos direitos autorais das músicas executadas. Os direitos autorais eram devidos em aproximadamente $30 \%$ das músicas da playlist, sendo que as demais eram de execução livre ${ }^{9}$. De acordo com informações da assessoria de imprensa do Metrô, reproduzidas em diversas matérias publicadas pelos meios de comunicação eletrônicos e digitais, para operacionalizar o sistema, a Companhia utilizou a infraestrutura já existente de alto-falantes usada para disseminar informações e orientações ao usuário.

Aliás, foi justamente baseando-se em um dos informativos frequentemente veiculados por meio do citado sistema de som, que usuários contrários à iniciativa argumentaram suas desaprovações. Eles se referiam ao aviso em áudio veiculado nos trens, cujo conteúdo orienta o usuário a usar fones de ouvido para o consumo de conteúdo sonoro ou audiovisual por meio de dispositivos como celulares e ou tablets. A orientação é respaldada pela Lei Municipal 15.937/2013, que proíbe o uso de aparelhos sonoros ou musicais no interior de veículos de transporte coletivo, o que inclui todos os tipos de veículos sobre trilhos que circulam dentro do município. O objetivo, segundo o aviso, é que a música de um passageiro não incomode os demais. Usuários partiam exatamente do mesmo argumento para questionar e criticar o projeto: "Isso me incomoda da mesma forma que quando alguém ouve música no celular sem fone. É aquilo que eles sempre proibiram e agora fazem". "[...] Entrei e ouvi aquela musiquinha chatinha e decidi comprar um fone ali mesmo para poder escapar. O Metrô fala para não perturbar e ele mesmo coloca música". ${ }^{10}$ Diante das reclamações, o Metrô partiu para o confronto e rebateu afirmando

${ }^{9}$ ICULT: ONG que tem atuação voltada para iniciativas ligadas à arte e cultura e está sediada na Avenida Paulista, São Paulo, desde 2004.

${ }^{10} \mathrm{CARDOSO}$, Willian. Nova Música ambiente nos trens é principal queixa dos usuários do Metrô de São Paulo - 18/09/2018. Disponível em: https://www1.folha.uol.com.br/cotidiano/2018/09/nova-musica-ambiente-nos-trens-e-principal-queixa-de-usuarios-do-metro-de-sp.shtml. Acesso em: $30 \mathrm{Abr} 2019$. 
que a lei mencionada é dirigida aos usuários e não ao operador do transporte e que a iniciativa tinha respaldo das avaliações positivas de quem "curtiu muito" ou considerou que a "música alivia a tensão e acalma"11.

A centralidade das discussões publicadas pelas diversas matérias que abordaram o Projeto Metrô +Música esteve ancorada em dois pontos. O primeiro no embate entre os usuários contrários ou favoráveis à presença da música nas estações e trens do Metrô. O segundo foi a contradição entre o que estabelecem as normas em relação ao uso de aparelhos sonoros por usuários dentro das instalações do Metrô e o uso da música como estratégia institucional. Por meio de uma postura de enfrentamento da rigidez das dicotomias apresentadas propomos uma reflexão, (ou uma “escuta cuidadosa") ${ }^{12}$ acerca do Projeto Metrô + Música a partir do reconhecimento do som como um importante elemento da dimensão urbana, mais especificamente, como um dos integrantes estruturadores dos diversos ambientes da cidade e das relações com os cidadãos.

\section{Projeto Metrô+Música: ambiente comunicacional, intencionalidades, disponibilidades}

Iniciamos retomando a constatação de que o som é um dos inúmeros elementos estruturadores da cidade. Os sons que compõem a complexidade do espaço urbano são expressões das práticas sociais e dos valores que o conformam. Talvez pela sua materialidade etérea e invisível, não figure dentre as principais preocupações dos gestores, empreendedores e até mesmo dos cidadãos que ocupam e fazem a cidade. Essa percepção é compartilhada pelo autor de Spaces speak, are you listening? Experience aural architecture (2009), Barry Blesser, para quem a cultura contemporânea orientada para a comunicação visual tem pouco apreço pela audição e, portanto, atribui pouco valor à consciência espacial sonora. A arquitetura sonora, ou "arquitetura aural" (aural architecture), como denomina Blesser, refere-se às propriedades de um espaço que podem ser experimentadas por meio da audição. Trata-se de um importante e negligenciado aspecto da estrutura espacial que "[...] pode influenciar nosso humor e associações. Embora possamos não estar conscientes de que a arquitetura aural seja em si um estímulo

\footnotetext{
${ }^{11}$ ESTARQUE, Marina. Música ambiente no Metrô deixa enfurecidos e relaxados - 12/08/2018. Disponível em: https://www1.folha.uol.com.br/cotidiano/2018/09/nova-musica-ambiente-nos-trens-e-principal-queixa-de-usuarios-do-metro-de-sp.shtml. Acesso em: 30 Abr 2019.

${ }_{12} \mathrm{Na}$ acepção schaferiana, escuta cuidadosa significa pensar sobre o que se ouve (SCHAFER, 2001).
} 
sensorial, reagimos a isso" $(2009$, p. 2).

E quando a presença do som se manifesta de forma desordenada e excessiva tornase um problema ambiental e de saúde. Em relatório divulgado em outubro de 2018, a OMS (Organização Mundial da Saúde) ${ }^{13}$ apresenta que a poluição sonora ultrapassou a água e agora ocupa o segundo lugar "como fenômeno indesejável e ameaçador ao bem-estar dos seres vivos do planeta”. Nessa análise já estão incluídas as fontes sonoras como turbinas eólicas, drones e o lixo sônico produzido por aparelhos eletrônicos que fazem parte de nosso cotidiano. A partir do momento em que o som ultrapassa os $50 \mathrm{~dB}$ (decibéis), nível considerado pela OMS como saudável ao ouvido humano, há a configuração da poluição sonora, sendo que a partir de $85 \mathrm{~dB}$ a intensidade do som começa a representar um perigo para a audição. A exposição ao ruído pode causar e/ou potencializar doenças como infarto, diabetes, pressão alta e outras.

São Paulo, considerada como uma das cinco cidades mais barulhentas pela OMS, atinge níveis entre 80 e $90 \mathrm{~dB}$ no horário de pico de trânsito e tem no transporte automotivo (particular e público) um dos principais emissores de ruídos. Portanto, circular pela megalópole do país representa um desafio também para a saúde mesmo que debaixo da superfície, como é o caso do sistema metroviário de São Paulo, cuja malha urbana é em grande parte construída em áreas subterrâneas. De acordo com pesquisa realizada pela SBO (Sociedade Brasileira de Otologia) em 2015 e em parceria com a PROTESTE ${ }^{14}$, a média de ruídos no Metrô de São Paulo é de 77,2 dB e, embora não alcance o limite considerado perigoso, acima de $85 \mathrm{~dB}$, o ruído já causa desconforto e tem potencial para desencadear irritação, fadiga, problema com concentração, estresse e até problemas cardíacos, conforme explica o médico otorrinolaringologista Paulo Roberto Lazzarini, presidente da SBO. Dentro desse contexto o que pode nos ensinar a proposta de veiculação de música nas estações e trens do sistema metroviário de São Paulo?

De acordo com dados obtidos por meio de matérias disponibilizadas e da Lei de Acesso à Informação junto ao SIC - Serviço de informação ao Cidadão do Metrô de São Paulo, o objetivo declarado foi o de "humanizar o ambiente". A Companhia explica que "O ponto de partida foi de que o Metrô é um ambiente de grande movimentação e aglomeração pública. A utilização da música como papel agregador e pacificador, criando ${ }^{13}$ Disponível em: http://www.euro.who.int/en/health-topics/environment-and-health/noise/environmental-noise-guidelines-for-the-european-region. Acesso em: 20 de junho de 2019.

${ }^{14}$ Pesquisa da PROTESTE mostra que barulho em transporte coletivo pode causar danos à saúde. Disponível em: https://www.proteste.org.br/carros-e-mobilidade/mobilidade-urbana/noticia/pesquisa-da-proteste-mostra-que-barulho-em-transportes-coletivos-pode-causar-danos-a-saude. Acesso em: 20 de junho de 2019. 
novas atmosferas a esses espaços, poderia ter um potencial transformador para o convívio social"15. (grifo nosso)

Destacamos da declaração a menção do Metrô como ambiente e questionamos qual é a compreensão de ambiente dos responsáveis pela proposta. Embora essa seja uma palavra de uso corrente, a discussão sobre seu significado e papel nos processos de comunicação contemporâneos tem ocupado pesquisadores e teóricos que perseguem a compreensão das práticas comunicativas para além das máquinas. Como nos adverte Norval Baitello Jr. (2018, p. 77), o conceito ainda precisa de "algum delineamento, ele possui muitas analogias com os conceitos de paisagem e cenário [...]. Tanto paisagem e cenário como ambiente denotam a presença de uma intencionalidade subjacente à criação de um entorno".

A intencionalidade declarada dos proponentes do Projeto Metrô+Música é criar "novas atmosferas" que tenham o "potencial transformador do convívio social". Para que se atinja o objetivo ou a intencionalidade proposta, nos parece relevante considerar que ambiente, como explica Baitello (2018), deriva do verbo latino ambire, que significa "cercar", "envolver". Tal compreensão implica considerar que a criação de um ambiente não pode ser confundida com o ato de criar um pano de fundo, mas sim "uma atmosfera gerada pela disponibilidade dos seres (pessoas e coisas), por sua intencionalidade de estabelecer vínculos" (2018, p.77). Nesse sentido, dentro da perspectiva de que todos, objetos e pessoas, atuam de forma dinâmica na construção do ambiente, a proposta da Companhia de construir um ambiente menos estressante se apresenta pouco atenta a um importante interagente desse processo, ou seja, o usuário contemporâneo do Metrô.

O usuário, ao ingressar nas estações e, principalmente, no interior dos vagões dos trens, ciente ou não, passa a integrar o ambiente, e "estar em um ambiente significa estar integrado a ele, configurando-o e sendo configurado por ele" (BAITELLO, 2018, p. 77). Portanto, ele é envolvido por materialidades e estímulos físicos que estruturam o espaço, assim como pelas corporeidades que, conjuntamente, ocupam e tendem a transformar o espaço em lugar. Ao mesmo tempo, sua postura, disponibilidade e intencionalidade atuam na conformação do ambiente que é fixo, ou seja, um espaço produzido, ordenado e controlado, e fluxo ao mesmo tempo. Fixo e fluxo são dois eixos do espaço geográfico que Milton Santos (1996) estuda como dinâmica que atinge as cidades contemporâneas. Como destaca Ferrara (124) “[...] a dinâmica dos fluxos impregna os fixos redefinindo-os,

15 Informação obtida pela autora por meio da Lei de Acesso à informação junto ao SIC - Serviço de informação ao Cidadão do Metrô de São Paulo. 
modificando-os, renovando-os até criar os lugares da cidade”.

Se considerarmos que o ambiente do Metrô é resultado da dinâmica dos fluxos, ou seja, da ocupação e da interação dos usuários entre si e com o espaço, torna-se importante observar que esses corpos estão literalmente de passagem e se apresentam atravessados por trânsitos mediáticos. Seja daqueles apresentados como representação visual em suporte bidimensional afixado na parede interna dos vagões, ou dos que são apresentados em telas de monitores eletrônicos estrategicamente instalados à altura dos olhos. Outro atravessamento a ser considerado é que as vozes descorporificadas (SCHAFER, 1991), que ressoam do sistema de som de cada vagão, disputam a atenção desses usuários frequentemente blindados com dispositivos e fones de ouvido particulares e conectados ao corpo. Como nos explica Obici (2008, p. 87-88), “esses celulares, tocadores de mp3, smarthphones passam a assumir um lugar que gera o conforto, a proteção, dos quais advém a flexibilidade de transitar pelos mundos". Para os usuários, em especial os contrários à veiculação de música dentro dos trens, além de viabilizarem o consumo em movimento de um conteúdo particularmente selecionado, esses dispositivos atuam como uma blindagem, ou como "operadores de [...] segurança, podendo criar mundos de fugas, escapes, que nos possibilitam suportar e lidar com o mundo ameaçador que nos cerca, sentido como caos" (OBICI, 2008, p. 87-88).

Portanto, nesse cenário nos parece que a esperada disponibilidade do usuário ficou parcialmente comprometida e tal postura não pode ser enfrentada como uma novidade ou surpresa se atento estiverem ao contexto de proliferação de aparatos midiáticos, de popularização de smartphones e de prestação gratuita de serviço de conexão sem fio para os usuários do Metrô de SP. Para além da apreensão de como tal contexto atua na conformação de hábitos e consumo de conteúdo, a construção de um ambiente favorável à proposta em questão, passa pela compreensão de que o usuário é interagente do ambiente que se deseja construir. Tal percepção subsidiaria ações nas quais o usuário não ocuparia a função de simples consumidor ou receptor cuja disponibilidade (passiva) seria expressa no simples gesto de ingresso às instalações do Metrô. Não há registro de pesquisa realizada pela Companhia junto aos usuários das linhas e estações que veiculavam música para aferir sobre a aceitação do projeto. Diante desse panorama é possível, portanto, considerar que a disponibilidade do usuário não tenha sido efetivamente compreendida e ou considerada e, que tal postura ainda tenha contribuído para outras compreensões sobre as intencionalidades do projeto. Vejamos, por exemplo, a percepção de especialistas 
publicada pelo Jornal Folha de São Paulo em agosto de $2018^{16}$, um mês após a implantação do projeto. Segundo eles, o Metrô recorreu à música para abafar os ruídos produzidos tanto pelos deslocamentos do ar, como pelo contato da roda com o trilho no momento do deslocamento dos vagões. "A técnica de disfarçar ruídos com sons harmônicos não funciona bem no Metrô. É um local barulhento. A música precisa ser muito alta e acaba sendo invasiva".

Embora considerada um recurso ineficiente para o mascaramento dos ruídos produzidos pelo próprio modal, recorrer à música como controle de sons pode ser compreendido como uma estratégia de natureza política do Metrô. A associação entre música e poder encontra ressonância em outra conjectura levantada pelos usuários. Trata-se da hipótese de que a música tenha sido usada como mecanismo de controle, ou seja, com a intenção de abafar as atividades musicais de artistas praticadas dentro dos vagões. Intensificado pelo contexto de recessão econômica, cada vagão carrega em si o potencial de ser transformado inventivamente em lugar de apresentação artística instantânea e ao vivo de artistas (amadores ou não) com instrumentos e ou apetrechos sonoros camuflados. Ou ainda, transformado em plataforma para ambulantes, que entre uma estação e outra entoam, em alto volume, bordões sobre as mercadorias que vendem clandestinamente. Nomeado por Schafer (2001, pp 114 - 115) como "sons imperialistas", o pesquisador explica que tal tática se dá por meio da modulação da intensidade e da espacialidade do som para se apropriar ou dominar o espaço, ou seja, aumentando o volume da música e garantindo que todas as saídas de áudio espalhadas em diversos pontos do vagão do trem estejam em pleno funcionamento, há a garantia de que os "sons imperialistas" e institucionais do Metrô sobressaiam ou mascarem as expressões sonoras institucionalmente indesejadas de ambulantes e artistas. Em ambos os casos apresentados na matéria, as intencionalidades (deduzidas) são bem diversas da declarada pelo Metrô, ou seja, a de "humanizar o ambiente".

É nesse ambiente plural, diverso, configurado por tensões, superposições e trânsitos mediáticos de diferentes naturezas que o Projeto Metrô+Música foi implantado. Ao se referir aos ambientes culturais da comunicação contemporâneos, Baitello Jr. nos chama a atenção para a relação entre a cultura, a valorização de um sentido e a construção de ambientes adequados a seus signos. Uma cultura da palavra, explica Baitello Jr. (2018,

${ }^{16}$ ESTARQUE, Marina. Música ambiente no Metrô deixa enfurecidos e relaxados - 12/08/2018. Disponível em: https://www1.folha.uol.com.br/cotidiano/2018/09/nova-musica-ambiente-nos-trens-e-principal-queixa-de-usuarios-do-metro-de-sp.shtml. Acesso em: 30 Abril 2019. 
p. 77-78) constrói ambientes adequados às temporalidades da leitura. E, reconhecendo a cultura contemporânea como a da imagem visual, a da "visualidade exuberante", explica que há a "construção de ambientes voltados para a hegemonia da visão, com todas as consequências que dela decorrem" (BAITELLO JR, 2018, p. 77-78). E sendo o Metrô integrante dessa complexidade, seria seu ambiente construído favoravelmente para as manifestações da imagem e não do som?

\section{Projeto Metrô+Música: adesão, imposição, afetação}

No contexto das mídias portáteis com conexão digital extensiva, da internet das coisas e da inteligência artificial, todos os "os ambientes em que vivemos hoje são indiscutivelmente mediáticos" (BAITELLO, 2018, p. 17). Não se trata, no entanto, de reduzir as mediações à lógica dos sistemas e aparelhos técnicos eletrônico-digitais, mas observar que sua expansão, acessibilidade e reprodutibilidade instantânea privilegiam a imagem visual que configura o que Baitello chama de "cultura da visualidade". Tal contexto, alerta-nos o autor, tende a nos levar a suspeitar do fato de "que estamos dispensando os outros sentidos que não a visão. [...] estamos nos coagindo ou sendo coagidos a esquecer que ouvimos" (BAITELLO, 2005, p. 99-100). Como observamos, o ambiente comunicacional do Metrô de São Paulo é tecido por usuários inseridos e atuantes nesse universo midiático híbrido e complexo, mas não significa que sejam impermeáveis, sobretudo, pela materialidade dos fenômenos sonoros que são apreendidos física, sensorial e simbolicamente.

Algumas particularidades sobre o estímulo sonoro e o ouvir. Além das já conhecidas propriedades - intensidade, altura e timbre, uma das características do som que merece nossa atenção para a discussão proposta é a sua natureza invasiva, ou seja, sua capacidade de superar os obstáculos e não respeitar a 'propriedade privada'. Por vezes, a janela antirruído ou o fone de ouvido não são suficientes para blindar espaços ou ouvidos de sons considerados indesejáveis. $\mathrm{O}$ som não exige exclusividade espacial e compõe o ambiente simultaneamente com múltiplas fontes sonoras. Seu caráter pervasivo e sua capacidade de gerar ambientes comunicacionais são destacados por Menezes (2016, p. 26): 
Da mesma forma como as vibrações sonoras ocupam ambientes no sentido físico do termo, podemos dizer que também geram ambientes comunicacionais nos quais é impossível não participar. Assim, sons ou vibrações favorecem um ambiente no qual os corpos envolvidos são afetados praticamente sem escolha, participam de forma mais ou menos profunda dos ambientes comunicacionais. (grifo nosso)

Na impossibilidade de escapar, o som, enquanto vibração de moléculas de ar, impacta o ouvido e o órgão de maior extensão do corpo, a pele. Como nos ensina Menezes (2016, p. 99), o ouvir, é, portanto, uma dinâmica do corpo. E na dinâmica interacional com o espaço, a natureza do ouvir possibilita o contato com o universo tridimensional, como nos orienta o antropólogo Christoph Wulf:

Enquanto a vista nos dá uma imagem do mundo em duas dimensões, o aspecto tridimensional do espaço manifesta-se através do ouvido. Enquanto a vista percebe apenas objetos que estão 'diante' dela, a orelha percebe sonoridades, tonalidade e timbres que se encontram atrás dela. Através do ouvido se desenvolvem o sentido e a consciência do espaço. A combinação do ouvido e do sentido do espaço, corresponde à implantação morfológica do sentido de equilíbrio na orelha. Com o ouvido nos 'localizamos' no espaço, garantimos o andar ereto e o equilíbrio (WULF, 2002, p. 464).

É nesse contexto que a música veiculada nas estações e trens do Metrô, enquanto expressão sonora, afeta o usuário-ouvinte de diversas formas. É sabido que a música atua no sistema límbico responsável pelas memórias, tomadas de decisões e emoções. No entanto, afetações, em especial, as emoções evocadas por uma música não são as mesmas para todos os ouvintes-usuários, pois tais conexões são individuais e dependem de inúmeros fatores como a cultura, as experiências e o histórico-sonoro-musical de cada um. Na musicoterapia, que atua com programas específicos para cada indivíduo (paciente), a música, usada de forma controlada, tem potencial para "restaurar, manter e aumentar a saúde mental ou física" ${ }^{17}$. No entanto, segundo o psiquiatra do Hospital das Clínicas de São Paulo Elko Perissinotti, "não há estudos comprobatórios de que a música

17AMTA, Associação Americana de Musicoterapia. Disponível em: https://www.musictherapy.org/about/musictherapy/. Acesso em: 15 maio 2019. 
em meio de transporte tenha benefícios"18 (ESTARQUE, 2018). Todavia, há registros sobre a experiência do uso da música como um 'sinal' decifrado pelo usuário como uma mensagem portadora de orientações sobre uma situação ou ação. Como exemplo dessa estratégia observamos a experiência realizada no Japão. A estratégia, em operação desde 1989 em trens e metrô de cidades como Tóquio e Osaka, utiliza avisos em forma de música para sinalizar o fechamento das portas das composições. Chamados de hassha merodii, o objetivo central é de avisar ao usuário a partida do trem sem causar ansiedade. Segundo pesquisas realizadas em 2008, após a adoção de melodias "houve uma queda de $25 \%$ no número de acidentes causados pela pressa dos passageiros, como correr para entrar num trem que está prestes a fechar as portas" (BALAGO, 2018) ${ }^{19}$. Vale destacar que cada hassha merodii dura sete segundos e que cada estação tem a sua, pois é levado em consideração fatores como a arquitetura da parada e a história dos bairros. "A ideia é que a soma dos sons de cada parada de uma mesma linha tenha coerência e forme uma espécie de música ao longo da viagem" (BALAGO, 2018).

No caso do Metrô de São Paulo, a experiência do ouvinte-usuário com a música ocorria durante todo o tempo em que permanecesse nas estações e nos vagões. Quanto à fruição ou não com o que era irradiado por meio da playlist, dependia de inúmeros fatores, dentre eles o do reconhecimento. Jazz, MPB, bossa nova, música erudita e samba configuravam uma seleção diversificada de gêneros musicais, cujos representantes eram versões de baixa e média estimulação. No entanto, a variedade de gêneros e de estimulação não parece ter viabilizado a continuidade do Projeto Metrô + Música e nos remete a outro fator que Felipe Trotta (2018) destaca como determinante sobre o tipo de experiência que o ouvinte tem com o som: "É necessário que o ouvinte esteja imbuído de certa adesão à experiência musical para que tal experiência seja vivenciada de forma adequada" (2018, p. 61).

Adesão, de acordo com o dicionário Houaiss, significa aceitação, aprovação. Portanto, antes mesmo do reconhecimento ou da identificação com as músicas que compunham a playlist, seria oportuno saber se foi considerada, no processo de planejamento

\footnotetext{
18 ESTARQUE, Marina. Música ambiente no Metrô deixa enfurecidos e relaxados - 12/08/2018. Disponível em: https://www1.folha.uol.com.br/cotidiano/2018/09/nova-musica-ambiente-nos-trens-e-principal-queixa-de-usuarios-do-metro-de-sp.shtml. Acesso em: 30 abr. 2019

${ }^{19}$ BALAGO, Rafael. Metrô do Japão usa músicas para acalmar passageiros e evitar acidentes. Disponível em: https:// avenidas.blogfolha.uol.com.br/2018/07/17/metro-do-japao-usa-musicas-para-acalmar-passageiros-e-evitar-acidentes/?loggedpaywall. Acesso em: 10 maio 2019.
} 
ou implantação, a possibilidade de os usuários não aprovarem a presença da música ou de se sentirem desrespeitados no direito deles de usufruir o percurso em 'silêncio', ou ainda, realizando outra atividade, como leitura ou cochilo. Em matérias publicadas sobre o assunto, é recorrente encontrar o registro de reclamações sobre o aspecto da imposição: "É a única hora que tenho para estudar. Isso tira a atenção"20.

Dadas as características do som como apontamos anteriormente, o usuário não conseguia escapar da música irradiada pelas caixas de som do Metrô e, em algumas linhas, mesmo usando fones de ouvido. E não se trata aqui de se reconhecer ou não com o gênero, embora muitos usuários não reclamassem das músicas, mas por se sentirem desrespeitados no que diz respeito ao direito à escolha. Nesse contexto, para os usuários que consideravam a estratégia como impositiva, é esperado que a postura deles não tenha se mostrado aberta à escuta, interface considerada pelo compositor e pesquisador Barry Traux (1984, p. 13-17 apud SANTOS, 2002, p. 33), como "crucial entre o indivíduo e o meio ambiente". Para o compositor, é preciso pensar a escuta como a interface primeira por meio da qual a informação é trocada entre o indivíduo e o meio ambiente. A escuta, para o autor, é "um caminho de troca de informações" e não apenas "uma reação auditiva a um estímulo" (IDEM). A escuta se diferencia do simples ouvir e está relacionada à intenção consciente de apreender as multiplicidades de sentido expressas pelos estímulos sonoros, sejam concretizados por objetos e corpos presenciais ou por vozes esquizofônicas irradiadas através de aparatos e dispositivos eletrônicos. Como nos ensina Barthes (2009, p.235) "ouvir é um fenômeno fisiológico; escutar é um ato psicológico".

As controvérsias geradas com a implantação e descontinuidade do Projeto Metrô+Música em São Paulo evidenciam que os sons ocupam espaço e expressam as disputas e as negociações em torno do uso e significado dos espaços de uso coletivo, públicos ou privados e, sobretudo, evidenciam a complexidade que envolve o processo de comunicação contemporâneo, em especial quando consideramos que é engendrado por uma rede diversificada de atores e interesses, por materialidades e dispositivos que juntos tecem um ambiente comunicacional plural, controverso e dinâmico, como o Metrô de São Paulo. Na balbúrdia sonora que envolveu a proposta, os usuários que se manifestaram favoráveis ao projeto, que aderiram à ideia e se reconheceram nas músicas veiculadas,

${ }^{20}$ ESTARQUE, Marina. Música ambiente no Metrô deixa enfurecidos e relaxados - 12/08/2018. Disponível em: https:// www1.folha.uol.com.br/cotidiano/2018/09/nova-musica-ambiente-nos-trens-e-principal-queixa-de-usuarios-do-metro-de-sp.shtml. Acesso em: 30 abr. 2019 
foram 'silenciados' pelo volume das queixas expressas e quantificadas ${ }^{21}$. Dentre as muitas lamentações, destacamos a objetividade da justificativa dos responsáveis para a descontinuidade do projeto. Foram exatas 13 palavras para lidar com a complexidade da comunicação e seu caráter probabilístico. Isso nos soa como sintoma de um discurso ensurdecido e, portanto, não aberto ao diálogo por meio do qual novas informações e percepções poderiam emergir e qualificar as práticas que envolvem o som na e da cidade.

\section{Considerações Finais}

Os ‘episódios’ envolvendo o Projeto Metrô+Música, dentre as inúmeras discussões que nos despertam, apontam para o seguinte questionamento: estamos ou não diante de uma nova conformação do que Baitello (2005) chamou de "tempo do fluxo"? Para o autor, a temporalidade do ouvir é a do fluxo lento. Ouvir, segundo Baitello, "requer um tempo do fluxo e o tempo do fluxo é o tempo do nexo, das conexões, das relações, do sentido e do sentir" (2005, p. 108). Considerando o contexto atual, o tempo do fluxo do ouvir é modulado por dispositivos, pela diversidade e multiplicidade de possibilidades de consumo, produção, compartilhamento e reprodução de sons que retroagem na forma como escutamos e nos relacionamos com o som em nossas atividades cotidianas. Em que medida o tempo do fluxo do ouvir do homem contemporâneo está mudando e nos impulsionando a refletir acerca das novas relações e significações que podemos ter com o som que produzimos e que na cidade nos envolve inexoravelmente? Passos para novas pesquisas.

\section{Referências}

AMARAL, Luiza Spínola. Áudio-imagem: estudo da comunicação auditiva segundo Joachin-Ernst Baerendt.Tese de Doutorado. PUC - Pontifícia Universidade Católica de São Paulo, 2016.

\section{BAITELLO JR, Norval. A carta, o abismo, o beijo. Os ambientes de imagens entre o artístico e o mediático. São Paulo: Paulus, 2018.}

\footnotetext{
${ }^{21}$ Por meio da Lei de Acesso à Informação, a Folha de São Paulo teve acesso aos dados relativos às reclamações dos usuários do Metrô após dois meses de implantação da ação Metrô+Música que revelou que de quatro queixas registradas, três eram por conta da música. De acordo com a matéria foram 1.674 reclamações (ou 80 por dia) das 2.299 recebidas. No comparativo com julho de 2017, quando não havia a presença da música, as reclamações registradas totalizaram 469. Outro comparativo pode se dar por meio dos números relativos ao segundo motivo de reclamações: a segurança. Foram 139 queixas, ou seja, 12 vezes menos que o primeiro motivo.
} 
BAITELLO JR, Norval.. A era da iconofagia Ensaios de comunicação e cultura. São Paulo: Hacker, 2005.

BARTHES, Roland. O óbvio e o obtuso. Lisboa: Edições 70, 2009.

BLESSER, Barry; SALTER, Linda-Ruth. Spaces speak, are you listening Experience aural architecture. Cambridge: MIT Press, 2009.

FERRARA, Lucrédia D'Alessio. Cidade: fixos e fluxos. In: TRIVINHO, Eugênio. Flagelos e horizontes do mundo em rede política, estética e pensamento à sombra do pós-humano. Porto Çaegre: Sulina, 2009.

MENEZES, José Eugenio de Oliveira. Cultura do ouvir e ecologia da comunicação. São Paulo: UNI, 2016.

MONTAGU, Ashley. Tocar: o significado humano da pele. São Paulo: Summus, 1998.

OBICI, Giuliano. Condição da escuta Mídias e territórios sonoros. Rio de Janeiro: 7 Letras, 2008.

PALLASMAA, Juhani. Os olhos da pele A arquitetura e os sentidos. Porto Alegre: Bookman, 2011.

TROTTA, Felipe. Música e conflito na cidade: práticas de escuta, espaço público e violência no Rio. In: FERANDES, Cíntia Sanmartin; HERSCHMANN, Micael. Cidades Musicais Comunicação, Territorialidade e Política. Porto Alegre: Sulina, 2018.

SANTOS, Fátima Carneiros dos. Por uma escuta nômade: a música dos sons da rua. São Paulo: EDUC, 2002.

SANTOS, Milton. A natureza do espaço: técnica e tempo, razão e emoção. São Paulo: Hucitec, 1996.

SCHAFER, Murray. A afinação do mundo. São Paulo: Editora UNESP, 2001.

SCHAFER, Murray. O ouvido pensante. São Paulo: Editora UNESP, 1991.

SILVA, Júlia Lúcia de O. A. da. Mergulho no escuro e outros mergulhos. Programas de auditório como ambientes radiofônicos. 2014. 131f. Tese (Doutorado em Comunicação e Semiótica), Pontifícia Universidade Católica, São Paulo.

SILVA, Maurício Ribeiro da; MENDONÇA, Carlos Magno Camargos; MENEZES, José Eugenio de O.; COELHO, Maria das Graças Pinto (Orgs.). Mobilidade, Espacialidades 
e alteridades. Salvador: EDUFBA, 2018.

WULF, Christoph. O Ouvido. GHREBH - Revista de Comunicação, Cultura e Teoria da Mídia. São Paulo, n 09, março 2007.

WULF, Christoph; BORSARI, Andrea (Orgs.). Cosmo, Corpo, Cultura: Enciclopedia Antropologica. Milano: Bruno Mondadori, 2002.

${ }^{i}$ Doutora em Comunicação e Semiótica pela PUC-São Paulo. Integrante do Grupo de Pesquisa Comunicação e Cultura do Ouvir da Faculdade Cásper Líbero de SP e do Grupo Rádio e Mídias Sonoras da Intercom. E-mail: julialuciaoliveira@gmail.com 